\title{
THE EFFECTIVENESS OF A PAIN MANAGEMENT PROGRAM ON INTENSITY OF PAIN AND QUALITY OF LIFE AMONG CANCER PATIENTS IN MYANMAR
}

\author{
Hein Thu*, Tintin Sukartini** \\ *Military Institute of Nursing and Paramedical Sciences, Myanmar \\ **Faculty of Nursing, Universitas Airlangga, Indonesia \\ Email: johnthu22@gmail.com
}

\begin{abstract}
Introduction: Cancer is one of the leading causes of death worldwide and is rapidly becoming a global pandemic. Cancer pain significantly affects the diagnosis, quality of life and survival of patients with cancer. The aim of this study is to analyse the effect of a Pain Management Program (PMP) on pain and quality of life in a patient with cancer. Methods: This study used a quasi-experimental design with a randomised pre-post test design approach. The data was collected from cancer patients in No 2 Military Hospital (500-Bedded), Yangon, Myanmar. The patients were recruited using a random allocation sampling technique and consisted of 30 respondents (experimental group) and 30 respondents (control group) taken according to the inclusion criteria. The Short Form-McGill Pain Questionnaire 2 (SF-MPQ 2) was used to assess pain, and The European Organization for Research and Treatment of Cancer Quality of Life Questionnaire-Core 30 (EORTC QLQC30) was used to assess the quality of life. Results: A MANOVA test was used to analyse the effect of PMP. It showed that 1) PMP decreased the pain and 2) PMP increased the quality of life in patients with cancer. Conclusions: Improvements in the quality of life and to do with pain-related cancer suggests that the vicious cycle of chronic pain may be alleviated by PMP. As we look at the results, PMP can be an effective treatment to be used by nurses for decreasing pain and increasing the quality of life in patients with cancer.
\end{abstract}

Keywords: cancer, Myanmar, pain management program, quality of life

\section{INTRODUCTION}

Cancer is a leading cause of death worldwide, having killed an estimated 8.2 million people in 2013 (World Health Organisation, 2014). World cancer reports estimate that the incidences of cancer will increase to 15 million new cases in 2020 (Ashton-Prolla et al., 2009). It was estimated that there were over 700,000 new cases of cancer and 500,000 cancer deaths in ASEAN member countries each year and that this number is expected to increase (Jan et al., 2012). In Myanmar, non-communicable diseases are estimated to account for $59 \%$ of the total deaths $(441,000)$ while the cancer mortality rate accounts for $11 \%$ (WHO, 2014).

Pain is one of the most common symptoms experienced by cancer patients; either because of the disease itself or the treatments that the cancer patients are receiving. Research has revealed that approximately $43 \%$ to $63 \%$ of cancer patients and $58 \%$ to $73 \%$ of those experiencing an advanced stage suffer from chronic pain during active cancer therapy (van den Beukenvan Everdingen et al., 2007). Unrelieved pain may prompt suicidal ideation among cancer patients. Therefore, pain is the most feared consequence for many cancer patients (Holtan et al., 2007). As much as $80 \%$ to $90 \%$ of cancer pain can be managed by various pharmacological and non-pharmacological methods (Breivik et al., 2009), yet it is regrettable that up to $40 \%$ of cancer goes untreated (Deandrea et al., 2008).

Quality of Life (QOL) can be described as the condition of well-being that consists of physical, psychological, social and spiritual aspects (Kyranou et al., 2013). Cancer patients not only experience physical problems, but also psychosocial and spiritual disorders that affect their quality of life (Manuaba, 2008). Higher pain intensity in cancer patients generally can cause symptoms of depression, anxiety, fatigue and stress. It can also contribute to the psychological factors that can affect the patient's pain experience and the quality of life of the patients (Vallerand et al., 2007). Therefore, care needs to be tailored to meet the needs of the cancer patients psychosocially that we can make pain management better and more functional.

Nowadays, pain management for cancer patients includes pharmacological and non-pharmacological methods. The World Health Organisation suggested a pain ladder for the treatment of cancer pain (WHO, 2014). Given the existence of all of these methods of cancer pain management, it is unfortunate when cancer pain goes untreated or undertreated (Deandrea et al., 2008). The Pain Management Program (PMP) is a treatment of 
choice which is based on the principles of cognitive behaviour for people with persistent pain that could make their quality of life worse. PMP aims to help clients manage pain better in the long term. PMP uses a combination of psychological, physical and practical methods to relieve the pain, physical disability and poor quality of life (The British Pain Society, 2013).

In a military setting, No 2 Military Hospital (500-Bedded) is responsible for the treatment of cancer patients and is one of the hospitals that can provide comprehensive treatment and healthcare facilities for the patients with cancer. As for the disease burden, according to the available data from the Medical Records Department of No 2 Military Hospital, 1,914 patients were admitted to the oncology ward in 2015. In general, thirty patients a day were treated with chemotherapy, and forty-seven patients were treated with radiation therapy daily.

According to Thiha (2014), among the cancer patients with pain, the most common cancers with pain are breast cancer $(27.4 \%)$ and lung cancer $(23.29 \%)$. According to the description of the pain, the most obvious type of pain is somatic in origin $(49.32 \%)$ and neuropathic pain at $13.7 \%$. The usual complaints of symptoms are lower back pain and chest pain. According to the duration of pain, chronic pain $(73 \%)$ is more common. Cancer ultimately affects $72.60 \%$ of all cancer patients among other causes of cancer pain, treatment, debility, concurrent disorder. According to pain scores, the respondents showed moderate pain as much as $58.9 \%$ and severe pain as much as $30.14 \%$. The results of the interviews with ten patients who were admitted to No $2 \mathrm{MH}$, Yangon, approved the statements made by officers of the department that patients often suffer from pain, especially after undergoing chemotherapy and radiotherapy. At the time of the interview, there were three nasopharyngeal cancer patients with severe pain. The patients seemed to cry and moan in pain, holding the hands of their relatives to face their dying days. Patients conveyed that the pain was felt at every moment, and it was so intense that they could not sleep or eat.

Regarding the hospital workload, about a hundred patients were admitted to the oncology ward and nine nursing personnel were assigned to this ward. The functions of the nurses in the oncology ward were mainly in a caregiver role focusing on direct health care services to the patients, health education to the patients and their families and supportive health care such as psychosocial support, spiritual care and symptom management (Medical Record Department, 2015).

Pain management is crucial in caring for cancer patients, and it involves medication as well as non-pharmacological therapies to promote comfort. Pain is the most common problem in patients with cancer, therefore giving effective and supportive treatment to those who suffer from pain is of critical importance. PMP has been developed by a team of health workers in the UK but is still not covering others. In addition, there has been no previous study applying PMP among cancer patients in Myanmar. The findings of this study can be applicable to the development of PMP to reduce the intensity of pain and to improve the quality of life among cancer patients in Myanmar, especially in the military setting. With regards to these results, the researchers recommend PMP as a form of alternative non-pharmacological therapy to reduce pain and to improve the quality of life of cancer patients in the No (2) Military Hospital (500-Bedded) Yangon, Myanmar.

\section{MATERIALS AND METHODS}

This study used a quasi-experimental design with a randomised pre-post test design approach. The data was collected from cancer patient in the No (2) Military Hospital (500Bedded), Yangon, Myanmar. The patients were recruited by using a random allocation sampling technique and consisted of 30 respondents (in the experimental group with PMP and routine care) and 30 respondents (in the control group with routine care) taken according to the criteria. The samples were taken using the consecutive sampling method with inclusion and exclusion criteria. The inclusion criteria were cancer patients with mild to moderate pain, cancer patients who were undergoing treatment, such as chemotherapy, radiotherapy, surgical and a combination of the above.

The independent variable was PMP. The dependent variables were pain and quality of life. Confounding variables were age, sex, job, income and education level. The Short 
Form-McGill Pain Questionnaire 2 (SF-MPQ 2) was used to assess the pain. This questionnaire consisted of a pain intensity scale ranging from 0 (none) to 10 (worst) (Dworkin et al., 2009). This instrument has been tested regarding its validity and reliability by Dworkin et al. (2009) and is widely used in many countries. The European Organisation for Research and Treatment of Cancer Quality of Life Questionnaire-Core 30 (EORTC QLQC30) that was used for assessing the quality of life had several components. Functional scales and symptoms were included in items number 1-28 with a score of 1 (never) to 4 (very often). Meanwhile, items number 29-30 were about their general health status with a score of 1 as very poor to 7 as very good. The Myanmar version of EORTC QLQ-C30 had been drawn up by EORTC itself.

The PMP survey was held for two weeks and was divided into four sections encompassing sections (1) education; section (2) guided practices, the implementation of progressive relaxation techniques; section (3) guided practices, the implementation of progressive visual distraction; section (4) evaluation. Each meeting took about 60 minutes. After all of the data was collected, the researchers conducted data analysis. The socio-demographic characteristics of the respondents were analysed using descriptive statistics. In addition, the MANOVA test was used to determine the effects of PMP and the confounding variables on pain and quality of life among respondents.

Approval and permission to conduct the study was obtained from the Research Ethics Committee of the Military Institute of Nursing and Paramedical Sciences, Myanmar, as well as a recommendation for the protection of human rights and welfare in medical research from the Ethical Committee of the Faculty of Nursing, Universitas Airlangga, Surabaya, Indonesia and also from the Commanding Officer of the Head of the Oncology Department and Nursing Superintendent of the No. (2) Military Hospital (500-Bedded), Yangon, Myanmar.

\section{RESULTS}

As shown in Table 1, there were a total of 60 respondents. 30 were in the control group, and 30 respondents were from the intervention group. The majority of the respondents from the intervention group $11(36.7 \%)$ were in the $46-55$ age group. In relation to the gender grouping, 17 (56.7\%) respondents were male. With regards to occupation, the highest proportion of respondents $(43.3 \%)$ were soldiers. All of the respondents were not only military soldiers'

Table 1: Distribution of demographic characteristics of respondents $(n=60)$ in Oncology Unit, No (2) Military Hospital (500- Bedded), Yangon, Myanmar

\begin{tabular}{|c|c|c|c|c|}
\hline \multirow[t]{2}{*}{$\begin{array}{c}\text { Character- } \\
\text { istics }\end{array}$} & \multicolumn{2}{|c|}{$\begin{array}{c}\text { Intervention } \\
\text { Group }(n=30)\end{array}$} & \multicolumn{2}{|c|}{$\begin{array}{c}\text { Control } \\
\text { Group }(n=30)\end{array}$} \\
\hline & $\mathbf{n}$ & $\%$ & $\mathbf{n}$ & $\%$ \\
\hline \multicolumn{5}{|l|}{ Age } \\
\hline 26 - 35 years & 4 & 13.3 & 3 & 10.0 \\
\hline $36-45$ years & 8 & 26.7 & 5 & 16.7 \\
\hline 46 - 55 years & 11 & 36.7 & 14 & 46.7 \\
\hline$>55$ years & 7 & 23.3 & 8 & 26.7 \\
\hline \multicolumn{5}{|l|}{ Sex } \\
\hline Male & 17 & 56.7 & 17 & 56.7 \\
\hline Female & 13 & 43.3 & 13 & 43.3 \\
\hline \multicolumn{5}{|l|}{ Job } \\
\hline Soldier & 13 & 43.3 & 13 & 43.3 \\
\hline Does not work & 12 & 40.0 & 14 & 46.7 \\
\hline Private & 4 & 13.3 & 3 & 10.0 \\
\hline Civil servant & 1 & 3.3 & 0 & 0 \\
\hline \multicolumn{5}{|l|}{ Rank } \\
\hline Family & 17 & 56.7 & 17 & 56.7 \\
\hline Other rank & 11 & 36.7 & 12 & 40.0 \\
\hline Officer & 2 & 6.7 & 1 & 3.3 \\
\hline \multicolumn{5}{|l|}{ Income* } \\
\hline$<200$ & 8 & 26.7 & 3 & 10.0 \\
\hline $200-400$ & 18 & 60.0 & 23 & 76.7 \\
\hline$>400$ & 4 & 13.3 & 4 & 13.3 \\
\hline
\end{tabular}

\begin{tabular}{lcccc} 
Education & & & & \\
Primary & & & & \\
Middle & 10 & 33.3 & 6 & 20.0 \\
High & 12 & 40.0 & 19 & 63.3 \\
Graduate & 2 & 6.7 & 4 & 13.3 \\
Can read or & 4 & 13.3 & 1 & 3.3 \\
$\quad$ write & 2 & 6.7 & 0 & 0 \\
\hline Intervention & & & & \\
Chemotherapy & & & & \\
Combination & 21 & 70.0 & 21 & 70.0 \\
$\quad$ therapy & 9 & 30.0 & 9 & 30.0 \\
\hline Diagnosis & & & & \\
Lung cancer & 10 & 33.3 & 11 & 36.7 \\
CA breast & 4 & 13.3 & 4 & 13.3 \\
CA cervix & 5 & 16.7 & 5 & 16.7 \\
CA rectum & 1 & 3.3 & 1 & 3.3 \\
Melanoma & 2 & 6.7 & 2 & 6.7 \\
Sarcoma & 2 & 6.7 & 2 & 6.7 \\
Sarcoma & 4 & 13.3 & 3 & 10.0 \\
CA tongue & 2 & 6.7 & 2 & 6.7 \\
\hline
\end{tabular}

* in thousand kyats 
Table 2: Differences in pain of cancer patients in intervention group and control (n: 60)

\begin{tabular}{cccccccccc}
\hline Variable & & \multicolumn{3}{c}{ N } & \multicolumn{3}{c}{ Intervention Group } & \multicolumn{4}{c}{ Control Group } \\
\cline { 3 - 11 } & & & Mean & SD & Min-Max & N & Mean & SD & Min-Max \\
\hline \multirow{2}{*}{ Pain } & Pre test & 30 & 4.07 & 1.14 & $2-6$ & 30 & 4.37 & 0.72 & $2-6$ \\
\cline { 2 - 11 } & Post test & 30 & 3.53 & 0.97 & $1-5$ & 30 & 4.7 & 0.92 & $3-6$ \\
\hline
\end{tabular}

Table 3: Differences in quality of life of cancer patients in intervention group and control $(n=60)$

\begin{tabular}{|c|c|c|c|c|c|c|c|c|c|}
\hline \multirow[t]{2}{*}{ Variable } & & \multirow[b]{2}{*}{$\mathbf{N}$} & \multicolumn{3}{|c|}{ Intervention Group } & \multicolumn{4}{|c|}{ Control group } \\
\hline & & & Mean & SD & Min-Max & $\mathbf{N}$ & Mean & SD & Min-Max \\
\hline \multirow{2}{*}{$\begin{array}{l}\text { Quality } \\
\text { of life }\end{array}$} & Pre test & 30 & 64.63 & 35.35 & $10-121$ & 30 & 70.83 & 30.86 & $11-118$ \\
\hline & Post test & 30 & 90.07 & 32.55 & $19-145$ & 30 & 71.27 & 23.16 & $29-115$ \\
\hline
\end{tabular}

and their wives but their parents and children. Regarding the source of information from the respondents, $56.7 \%$ were family members of military soldiers. Almost two thirds, $18(60 \%)$ of the respondents, earned 200,000-400,000 kyats as their family income per month. The highest group of respondents in the intervention group (40\%) had a middle school education level. More than two thirds, $21(70 \%)$, were undergoing chemotherapy. In addition, most of the respondents from the intervention group (10) (33.3\%) were lung cancer patients.

According to Table 1, the data in the control group showed that most of the respondents $(n=14,46.7 \%)$ were in the 46-55 years age group, and most of them $(56.7 \%)$ were male respondents. 14 out of 30 of the respondents (46.7), and 17 out of $30(56.7 \%)$ were family members of military personnel. With regards to family income, more than twothirds of the respondents $(76.7 \%)$ earned $200,000-400,000$ kyats per month. $63.3 \%$ of respondents had a middle school education level. Likewise in the intervention group, 70\% of the total respondents were undergoing chemotherapy, and 11(36.7\%) respondents were diagnosed with lung cancer.

As shown in Table 2, the mean pain score of the cancer patients in the intervention group was 4.37 , and it decreased to 4.07 . The control group gained a mean pain score in the pre-test of 4.07, and post-test this score was 4.37. It can be seen that the control group had a higher mean score of a pain than the intervention group.

Based on Table 3, the mean score of the quality of life of cancer patients in the intervention group was 64.63, and this increased to 90.07 , while the control group mean score of the quality of life in the pretest was 70.83 and post-test were 71.27. The results showed that the intervention group had a higher mean score of quality of life than the control group.

Based on Table 4, it can be seen that, in general, there are differences in mean pain and the quality of life between the treatment and control groups. The results show that the value of Hotteling's trace sig. 0.000 was smaller than $\alpha 0.05$, so it is stated that there was a difference in pain and quality of life between the treatment group and the control group.

Table 5 shows that there was a difference in pain with $p=0.000$ and quality of life with $\mathrm{p}=0.013$ between the treatment group and the control group. However, there was no significant difference between the functional scales $(p=0.186)$ and the symptomatic scales of quality of life $(p=$ 0.051 ). There was only a significant difference in the general health scales $(\mathrm{p}=0.000)$. It can be seen that PMP reduces pain and improves QOL only in relation to the general health scales.

\section{DISCUSSIONS}

The findings of this study confirmed that PMP reduced the intensity of pain in cancer patients. Compared with the patients from the control group, the pain scores were significantly reduced. We found that the worst pain intensity in the intervention group was lower than in the control group and this showed a significant difference. These findings are in accordance with earlier studies that found that PMP decreased patients' pain.

Based on the research conducted by Tse et al. (2012) on patients in palliative care and cancer patients hospitalised in Hong Kong, it was found that after the implementation of a PMP (using PRN drugs and non-pharmacological methods), the pain 
The effectiveness of a pain management... (Hein Thu, Tintin Sukartini)

Table 4: Differences test between intervention and control group $(n=60)$

\begin{tabular}{clcccc}
\hline Effect & & Value & F & Hypothesis df & Sig \\
\hline PMP & Pillai's trace & 0.284 & $11.293^{\mathrm{b}}$ & 2.000 & 0.000 \\
\hline & Wilk's lambda & 0.716 & $11.293^{\mathrm{b}}$ & 2.000 & 0.000 \\
\hline & Hotteling's trace & 0.396 & $11.293^{\mathrm{b}}$ & 2.000 & 0.000 \\
\hline & Roy's largest root & 0.396 & $11.293^{\mathrm{b}}$ & 2.000 & 0.000 \\
\hline
\end{tabular}

Table 5: Results of analysis between intervention and control group $(n=60)$

\begin{tabular}{ccccc}
\hline Variable & Mean Square & $\boldsymbol{D} \boldsymbol{f}$ & $\mathbf{F}$ & $\boldsymbol{P}$ value \\
\hline Pain & 20.417 & 1 & 20.417 & 0.000 \\
\hline QOL & 5301.600 & 1 & 5301.600 & 0.013 \\
\hline QOL- FS & 299.267 & 1 & 1.789 & 0.186 \\
\hline QOL- SS & 303.750 & 1 & 3.979 & 0.051 \\
\hline QOL- GH & 1440.600 & 1 & 14.041 & 0.000 \\
\hline
\end{tabular}

scale decreased significantly in the two groups (intervention and control), as well as significantly so in decreasing the barrier to pain management. Pain is influenced by several factors. Some of the factors that affect pain include physiological factors (age, gender, weakness or fatigue, genes, neurological function), social factors (attention, previous experience), spiritual factors, psychological factors (anxiety, coping technique), and cultural factors (meaning of pain, ethnicity). In the present study, the decrease in pain intensity after the PMP could be interpreted as a positive for patients with cancer. Because the treatment of chronic pain in many cancer patients is difficult, this positive effect of PMP on pain intensity can be considered to be clinically important (EORTC, 2003). According to the findings of this study, as well as in previous studies, we can conclude that performing PMP for patients with cancer can indirectly lead to the acceptance of pain for the patients as they mentioned in the sessions, or indirectly assist the healthcare providers in reducing the patient's pain. It is better to use non-pharmaceutical treatment alongside medication for the better management of pain (Aubin et al., 2006; Lai et al., 2004).

Based on the findings of this study, a majority of the respondents from the intervention group had quality of life in the poor category before being given the PMP, as found through The European Organisation for Research and Treatment of Cancer Quality of Life Questionnaire-Core 30 (EORTC QLQC30) (Scott et al., 2008). Cancer is a lifechanging thing. For some people, cancer provides opportunities to self-introspect and enhance the meaning of life. But overall, cancer will affect the physical, social, psychological, and spiritual well-being of individuals (Potter \& Perry, 2010). According to Fitriana and Ambarini (2012), most cancer patients feel that they are in a period of crisis that requires adjustment, and each patient will require different adjustments depending on their perceptions, attitudes and personal experiences related to self-acceptance to change. According to the researcher, the changes associated with the disease condition experienced were received differently in each patient, so this condition will affect the quality of life of cancer patients.

In relation to the principle scoring of EORTC QLQ-C30, high scores showed that the higher the level of quality of life means a high score on a functional scale which showed that the higher the level of function of health, means that a high score in the health status and a generally high quality of life. A high score on the symptom scales showed a higher the level of problems or existing symptoms (Aaronson et al., 1993). In addition, there is also the research and arguments indicating the influence of cultural factors on quality of life. In this study, by comparing the mean quality of life scores between both groups before and after the intervention, the patients' quality of life improved in the intervention group and decreased in the control group. Based on our results after the intervention, the scores related to the quality of life and general health scale increased significantly in the intervention group, while the functional scale and symptoms scale did not differ significantly 
compared with the control group. Liang et al. (2015) revealed that the patients' reports of pain intensity and pain interference were significantly correlated with quality of life. Participants who experienced higher levels of pain and interference reported lower levels in the functional and global domain of quality of life and a higher level in the symptom domain of quality of life. The findings of this study showed that PMP reduced the intensity of pain in cancer patients. Compared with patients from the control group, the pain scores were significantly reduced. It can be concluded that reducing pain intensity reflects an improving quality of life in cancer patients with pain.

Indeed, in patients who received PMP, the pain scores were significantly reduced, and there were improved QOL scores after 2 weeks compared with those who received standard care in this study.

\section{CONCLUSIONS}

To the best of our knowledge, this is the first study evaluating the effects of PMP in cancer patients experiencing pain in Myanmar. The results of the present study showed that PMP decreased pain intensity and improved the quality of life of cancer patients. It is suggested that if it is introduced into clinical practices of standard care, this type of PMP could have the potential to improve the quality of pain management for the great majority of cancer patients. However, this study had some limitations. Findings from this study may not be generalised to cancer patients in other settings or other countries. Furthermore, the present study population was drawn from cancer patients from a military setting. Therefore, the generalisation of these findings to individuals living in other geographic regions is limited. Also, we studied a relatively small number of patients with cancer who had pain at a single institution. Future studies may follow on from this study with a larger sample size from multiple institutions. In addition, we suggest a further comparison of the effectiveness of PMP with other types of nonpharmacological pain interventions among cancer patients.

\section{REFERENCES}

Aaronson, N. K. et al. (1993) 'The European Organisation for Research and Treatment of Cancer QLQ-C30: A quality-of-life instrument for use in international clinical trials in oncology', Journal of the National Cancer Institute, 85, pp. 365-376. doi: 10.1093/jnci/85.5.365.

Ashton-Prolla, P. et al. (2009) 'Development and validation of a simple questionnaire for the identification of hereditary breast cancer in primary care', BMC Cancer, 9(1), p. 283. doi: 10.1186/1471-2407-9-283.

Aubin, M. et al. (2006) 'Impact of an Educational Program on Pain Management in Patients With Cancer Living at Home', Oncology Nursing Forum, 33(6), pp. 1183-1188. doi: 10.1188/06.ONF.1183-1188.

van den Beuken-van Everdingen, M. et al. (2007) 'Prevalence of pain in patients with cancer: a systematic review of the past 40 years', Annals of Oncology, 18(9), pp. 1437-1449. doi: 10.1093/annonc/mdm056.

Breivik, H. et al. (2009) 'Cancer-related pain: a pan-European survey of prevalence, treatment, and patient attitudes', Annals of Oncology, 20(8), pp. 14201433. doi: 10.1093/annonc/mdp001.

Deandrea, S. et al. (2008) 'Prevalence of undertreatment in cancer pain. A review of published literature', Annals of Oncology, 19(12), pp. 1985-1991. doi: 10.1093/annonc/mdn419.

Dworkin, R. H. et al. (2009) 'Development and initial validation of an expanded and revised version of the Short-form McGill Pain Questionnaire (SF-MPQ2)', Pain. International Association for the Study of Pain, 144(1-2), pp. 3542. doi: $10.1016 /$ j.pain.2009.02.007.

Fitriana, N. A. and Ambarini, T. K. (2012) 'Kualitas Hidup Pada Penderita Kanker Serviks Yang Menjalani Pengobatan Radioterapi', Jurnal Psikologi Klinis dan Kesehatan Mental, 1(2), pp. 123-129.

Holtan, A. et al. (2007) 'Prevalence of pain in hospitalised cancer patients in Norway: a national survey.', Palliative Medicine, 21(1), pp. 7-13. doi: $10.1177 / 0269216306073127$.

Jan, S. et al. (2012) 'The socioeconomic burden of cancer in member countries of the Association of Southeast Asian Nations (ASEAN)--stakeholder 
meeting report', Asian Pacific journal of cancer prevention: APJCP, 13(2), pp. 407-409. doi: 10.7314/APJCP.2012.13.2.411.

Kyranou, M. et al. (2013) 'Differences in depression, anxiety, and quality of life between women with and without breast pain prior to breast cancer surgery', European Journal of Oncology Nursing, 17(2), pp. 190195.

doi: 10.1016/j.ejon.2012.06.001.Difference s.

Lai, Y. et al. (2004) 'Effects of brief pain education on hospitalized cancer patients with moderate to severe pain.', Supportive Care in Cancer, 12(9), pp. 645-652. doi: 10.1007/s00520-004-0626-1.

Liang, S. Y. et al. (2015) 'The impact of pain on the quality of life of Taiwanese oncology patients', Pain Management Nursing. American Society for Pain Management Nursing, 16(2), pp. 128136. doi: 10.1016/j.pmn.2014.05.009.

Mahamed, F. (2012) 'Impact of Family Planning Health Education on the Knowledge and Attitude among Yasoujian Women', 4(2), pp. 110118. doi: $10.5539 /$ gjhs.v4n2p110.

Manuaba, T. W. (2008) Masalah Kanker di Indonesia. Universitas Udayana.

Medical Record Department (2015) Admission rate of oncology ward. Yangon.

Scott, N. W. et al. (2008) 'EORTC QLQ-C30 Reference Values', EORTC Quality of Life Group, (July), p. 419. Available at: https://pdfs.semanticscholar.org/71d3/ de2b6d58bf321da160a43a99777538a2 06d8.pdf\%0Ahttp://groups.eortc.be/qo 1/sites/default/files/img/newsletter/refe rence_values_manual2008.pdf.

The British Pain Society (2013) Cancer Pain Management: A perspective from the British Pain Society, supported by the Association for Palliative Medicine and the Royal College of General Practitioners, The British Pain Society's Cancer Pain Management. London: The British Pain Society.

Thiha, S. (2014) Clinical Study of physical Pain in Cancer Patients. DSMA, Mingalardon.

Tse, M. M. Y. et al. (2012) 'The Effect of a Pain Management Program on Patients With Cancer Pain', Cancer Nursing, 35(6). Available at: http://journals.lww.com/cancernursing online/Fulltext/2012/11000/The_Effec t_of_a_Pain_Management_Program_o n.7.aspx.

Vallerand, A. H. et al. (2007) 'Factors that affect functional status in patients with cancer-related pain', Pain, 132(1), pp. 82-90. doi: https://doi.org/10.1016/j.pain.2007.01. 029.

WHO (2014) Noncommunicable Diseases (NCD) Country Profiles. Geneva. doi: 10.4135/9781412994170.n207.

World Health Organization (2014) Cancer pain relief, Cancer pain relief. Available at: papers://d30f2a22-a1cf4822-9292-

0ad49fba75fc/Paper/p1288. 